\title{
Women's Strategies for Survival: Developing Agency in Abusive Relationships
}

\author{
Lora Bex Lempert ${ }^{1}$
}

The simultaneity of love and violence in the lived experiences of abused women
forms the context within which these women construct meaning and develop
agency. Utilizing grounded theory methodology (Glaser, 1978; Glaser and
Strauss, 1967; Strauss, 1987; Strauss and Corbin, 1990), this paper explicates
these agentic processes by analyzing the strategies employed by 32 abused
women, publically and privately, to mitigate the violence and its effects. By
highlighting the contradictory duality in these relationships, the processes by
which abused women strategize and develop agency to halt, change, andlor
cope with the violence becomes analytically salient. KEY WORDS: abuse; agency; battering; domestic violence; wife abuse; violence.

\section{INTRODUCTION}

There is widespread agreement among feminist scholars that violence and the threat of violence are gendered social acts that establish and maintain the control of men over women (as well as over other men), and that support for these acts is built into culture and socialization in many, if not most, societies (Hanmer and Maynard, 1987; Radford, 1987; Sheffield, 1989; Valentine, 1990). Because violence against women is so deeply embedded in the institutional fabric of society, wife abuse is both a social problem and a personal issue, as it is perpetrated by men against women in their social locations as wives and/or intimate partners. As a social problem, it can be viewed as a point of convergence of broader patterns of economic, social, and political discrimination against women.

\footnotetext{
'The University of Michigan-Dearborn, Department of Behavioral Sciences, Dearborn, Michigan 48128-1491.
} 
Like other social problems, abuse within intimate relationships develops over time. Yet, it is the precisely the processual nature of intimate violence that has been routinely obscured by the static quality of the dominant research models of "domestic violence," which typically count the discrete incidents of abusive behavior of various types (pushes, slaps, hits, kicks, etc.) to derive aggregate measures (e.g. Gelles and Straus, 1979; Straus and Gelles, 1986; Straus et al., 1980). Sociologically, when the analytic focus remains centered on the violence, the analyses also remain descriptive renditions of particular subsets of larger interactive relationships. Consequently, not only are the power differentials between the partners rendered invisible, but so too is temporality, and the analyses ultimately do not reflect the dynamic nature of abuse. For most women, abusive episodes are only a portion of the complex interactions with their partners that also involve significant acts of caring and mutual support (Lempert, 1992, 1995). Simply counting acts of violence misses the sociological mark by not counting (or accounting for) the affectionate aspects of the relationships.

Many theories developed to explain wife abuse have contributed to an understanding of the whole of this complex dynamic [see Walker (1979, 1989) on psychosocial cycle of violence theory; Straus et al. (1980); Straus and Gelles (1986) for culture of violence theory; Pagelow (1987) for social learning theory; Giles-Sims (1983) for general systems theory; Dobash and Dobash (1979, 1981, 1992); Martin (1976) for conflict theory; Straus (1977); Allen and Straus (1980) for ultimate resource theory]. Yet, none is complete. Some neglect structural and historical contexts of abuse; some fail to address the social legitimation of male violence against women (and others); some confound wife abuse with other forms of familial violence; and some fail to include the women's voices in their analyses. All fail to account for the simultaneity of love and violence that is the context for abuse in intimate relationships.

Intimate interpersonal violence is set within contradictory interactional contexts, that is, abused women hold oppositional beliefs in their partners as their sole sources of love and affection and, simultaneously, as the most dangerous persons in their lives. This research expands the survey and interview observations of previous researchers by explicating this contradictory duality in abused women's definitions (i.e., the paradox of love and violence). For it is this simultaneity that must be grasped analytically to understand how abused women strategize and develop agency to halt, change, and/or cope with the violence.

Abused women are active, although not co-acting equals, in the interactions with their partners; in the development of their own strategies to halt, change, and/or cope with the violence; and in the constructions and reconstructions of their relationships and their senses of self. As such, they 
are persistent in strategizing to preserve a sense of self-worth and agency within the structural conditions of violence. In presenting the processes of preserving and enhancing agency, of developing definitions and survival strategies, the present study provides an analysis of techniques employed by abused women to cope with the violence and its contradictions. First, the women's complicity in rendering the violence invisible to others, including face saving strategies, contradictory beliefs, and interactive processes, as well as the strategies used by both parties to keep their problematic interactions private, are considered. Next, how abused women attempt to contain the violence and to preserve their own agency is examined. The analysis then focuses on the women's voluntary attempts to make the intimate violence known to others, highlighting the negative consequences of their own and their partners' previous strategies of concealment.

\section{METHOD}

The present analysis is grounded in in-depth interview data from 32 women who reported experiencing repeated interpersonal violence, of a physical, psychological and/or emotional nature, at the hands of their intimate male partners. The self-selected respondents came from an outreach support group, an ancillary service to a women's shelter, for women who had left their abusive partners, or who were attempting to cope with, change, or terminate their relationships before they became acute and required emergency medical treatment. While the particularities of a small, self-selected, "visible" sample of abused women (i.e., women who self-identified by attending a support group), limit the generalizability of the data, it is precisely these women participants of outreach groups who can provide clues to programs for reaching the "invisible" victims.

For the purpose of this study, abuse was defined as the repeated use of physical, emotional, or psychological force by a man against his intimate female partner. This definition thus includes violence against both wives and unmarried female partners and further establishes abuse as a gendered social problem (Loseke, 1987). It also accounts for culturally determined and socially sanctioned heterosexual relationships. Additionally, the range of force reported forms a continuum of abuse (Kelly, 1988) from verbal degradation and humiliation to the severe psychological abuse of threats of murder and/or suicide, from slaps and pushes to assaults with weapons.

The 32 participants ranged in age from 21 to 57 years. Nine were women of color. I have assumed gender salience in the experiences of these women, that is, victimization as female partners transcending issues of race 
and/or ethnicity, although a larger sample of cross-race comparisons would be needed to test this assumption.

Four respondents were currently married to their abusive partners. Eleven identified themselves as single, six as divorced, and 11 as separated and in process of divorce. Four respondents had never lived with the abusing males. Eight women were living with their violent partners at the time of the interview. The length of time spent in the abusive relationships ranged from four months to 14 years.

Most participants had some college education. Only three women had less than a high school education, while 23 had two years or more of college. There were eight Bachelor of Arts or Science graduates, one registered nurse, one respondent with a masters degree, and one respondent with two Masters degrees. The minimal grade level achieved by the least educated respondent was eighth.

Most respondents were under-employed given their educational achievements; thirteen were unemployed. Two were employed in "blue collar" occupations (i.e., video technician and transit operator). Twelve were in "pink collar" jobs such as secretarial, bank tellers, service managers. Only five were in "white collar" employment situations as teachers, an architect, an interior designer, and a vice president of a brokerage institution.

Interviews ranged in duration from 1 to $41 / 2 \mathrm{hrs}$. All interviews were taped and most were transcribed. Participants responded to such openended probes as: "Tell me the story of this relationship." They were thus able to construct the narrative in their own terms as they currently understood it. In most cases, their retelling was episodic and provided significant insights into the history of their own developing awarenesses of the scope of the problem.

In this analysis, symbolic interactionist theory is integrated with feminist theory and grounded theory methodology (Glaser, 1978; Glaser and Strauss, 1967; Strauss, 1987; Strauss and Corbin, 1990) to emphasize the importance of respondents' own versions of reality, the meanings they construct and apply to their experiences, and to articulate the processes of data collection and analysis. Symbolic interactionism and grounded theory methodology allow for the emergence and development of substantive theory that addresses the limitations of the earlier theoretical formulations. Because this analysis focuses on the how of lived experience, it is framed interactionally (Denzin, 1989) and attempts to unravel the multiple meanings that derive from interactional events while simultaneously considering the surrounding contexts, or structural conditions. Feminist theories expand these perspectives by placing women and their experiences at the center of the analysis. Thus, in effect, feminist theories reshape the pursuit of knowledge about women and wife abuse (see Dobash and Dobash, 1979, 
1981, 1992; Ferraro, 1987; Hanmer and Maynard, 1987; Kurz, 1989; Loseke, 1987; Pagelow, 1981).

Interviews were conducted and analyzed utilizing grounded theory methodology (Glaser, 1978; Glaser and Strauss, 1967; Strauss, 1987; Strauss and Corbin, 1990) which stresses discovery and theory development. In grounded theory, both the processes and the products of research are shaped from "sensitizing concepts" in the data, rather than from preconceived theoretical formulations.

Grounded theory methodological practices are distinctive (Strauss and Corbin, 1990). Interviews and analysis occur simultaneously (Glaser and Strauss, 1967; Strauss and Corbin, 1990). Questions and observations are shaped through analytic interpretations and discoveries. Emerging patterns and ideas are checked and expanded in subsequent interviews thus strengthening both the quality of the data and the ideas developed from it (Charmaz, 1983).

Coding, in which data are categorized and sorted, is the initial phase of the analytic method. Codes were developed out of the analysis of the interviews, my field notes, and other collected materials. Examples of codes used were: problem solving strategies, retrospective knowledge, locked in, trade offs, and reality maintenance; also included were some in vivo codes like "I just leave" for dissociation episodes. Codes thus reflect conceptual (not descriptive) categories which emerge from the data. They are carefully defined, with delineated properties, explicated causes and consequences identifying the conditions under which social phenomena do and do not occur and thus provide for a range of variation. Further refining and improvement of the conceptual categories and their interrelations allows for the development of theories that capture and reflect lived experience.

In grounded theory, codes fit the data rather than forcing data into preconceived codes thus allowing for greater accuracy and a clearer rendering of the experiences (Charmaz, 1983). The categories developed are not treated as distinct units; rather, they are woven together into a processual analysis through which experience can be abstracted and explicated. Codes provide the "pivotal link" between the interview data and its conceptual rendering (Charmaz, 1983) and as such are the fundamental means of developing the analysis. Finally, theoretical sampling is used to check the scope and depth of a category by examining all the data that it covers and the variations from it. Selective theoretical sampling refines, elaborates, and exhausts conceptual categories (Glaser, 1978; Glaser and Strauss, 1967; Strauss and Corbin, 1990). Grounded theory methodology thus provides the means to develop rich substantive analysis. 


\section{INVISIBLE VIOLENCE}

The violence experienced by the women in this study frequently began in the initial stages of the relationships, in definitional dialogues that occurred between the women and their partners. These dialogues presaged the overt physical violence that later permeated their lives. Throughout the courses of their relationships, the men characterized their partners as "cunt," "whore," "asshole," "career woman hag," etc., defining both the women and their social situations. Respondents indicated that such accumulated challenges to their senses of self resulted in confusion over the loss of their referent bases:

After [he] had called me a cunt, it really bothered me and (sighs) my perception was so screwed up, I didn't know what was right and wrong anymore in the relationship. Whether it was OK for him to do that or not (Respondent 16).

In response to the characterizations, the women consciously modified their actions to alter their partners' definitions. Most did not report telling anyone about the verbal abuse and most did not report asking for help.

Instead, they tried to make their realities and the abusers' definitions consonant within their own definitional frames of family as a symbol of stability. Americans want to believe that the family is a loving, kind, and supportive haven, a place of nurturance where they can get away from the stress of the public sphere (Lasch, 1978). This "deep vein" in American civil life (Mintz and Kellogg, 1988) is related to social order in a basic and primordial way. Maintenance of the cultural tradition is presumed to be a responsibility of wives and is a taken for granted factor of American domestic life (Bernard, 1975; Hickey, 1990; Rubin, 1983; Skolnick and Skolnick, 1992). This ideological responsibility was often reflected in women's reports of maintaining the appearances of their relationships to others as nonviolent and harmonious-at least part of the time:

You don't want people to know that you're not happy, or in the beginning, I didn't want people to know that we weren't a happy couple. And then later on I didn't want people to know about the sexual abuse (Respondent 6).

In so doing, they supported the men's public authenticities, rendering the violent actions invisible to other parties. Male partners were reported to have defined both the verbal and physical interactions as non-violent and as victim provoked. While women initially accepted blame, their definitions became increasingly untenable as the abuse escalated:

So I didn't really, you know, consider that it was his fault. I always said it was my fault, that $I$, that something I did to provoke him and stuff like that. And I wasn't the type of person, you know, just walk out and leave, you know. I'd rather do a lot of things to sort out the problem and work it out. If it was my problem then I'll try as much as I can to avoid the violence, you know, I would 


\begin{abstract}
go to any length to please the man so he won't go to the out rage...The husband comes first to please the man that you're married to 'cause you committed yourself. So I always cover the batter situation, the abuse, because that's included in the relationship. That's included in the marriage that you committed yourself. No matter what happen you have to stand by your man. Even though I always covered the abuse part, I wasn't happy. I wasn't happy in that relationship, but I made a commitment to him that I would take care of that no matter what happened. I have to stand by that...Even though I be an angel and it didn't help at all...it just seemed like the more I stayed there, the more frustrating and provoked he get, the more it [violence] gets worse...And that me living here will trigger more hate, more anger within himself that he will never change (Respondent 12).
\end{abstract}

The men's denials of the women's definitions of their own reality became, in the words of many women, "crazy making." In the stories that the women told, the abusers' realities, the abusers' definitions, and the appearances of the relationships as harmonious were consonant. The women reported that for the men, there was apparently no contradiction between the appearance of harmony and the reality of violence. The men frequently denied that their actions were violent or abusive. The denials were predicated on the severity, not the legitimacy, of the assaults as this brief exchange shows:

In the end, I said, 'You're abusive.' And he said, 'You want abuse? I'll knock all your teeth out' (Respondent 11).

For the women, these nonviolent definitions and the violent realities did not match. They struggled verbally in interactions with their mates and with themselves over the definitional inconsistencies, but initially they did it alone. Choosing not to tell others generated feelings of complicity in the violence and rendered the men's actions invisible to outsiders.

\title{
Face-Saving
}

Maintaining invisibility is a face-saving strategy (Lester, 1983). It's a way for abused women to claim their senses of self. In preventing the images of the men's abuse from becoming public, the women simultaneously veiled their own images as victims. Naming is how the unknown becomes the known. What remains unnamed is non-existent (DuBois, 1983; Keller, 1985), and what is rendered invisible to outsiders has no reality.

Invisibility was employed to avoid destroying the credibility of the definition of the situation. It involved a course of action designed to elicit desired interpretations and responses. It was an impression management strategy (Goffman, 1971) used to affect other people's perceptions of the problematic interactions, as this respondent indicated: 
But they [neighbors] would come over and sit around and talk and stuff and it got to be kind of a joke that [partner] would say, Oh yeah, well you know it's Sunday, I beat her up on Sunday. Cause that's, he always did on Sundays-he'd do it other days too but it-like there was never a Sunday that went by the whole time we were married possibly that he didn't like beat me up or just go crazy and start screaming and yelling and threatening, and I sat there and I remember, oh yeah, you know, on Sundays he beats me up, and now, you know, and I kind of joked about it, you know, and these people were sitting there and they were, oh, they thought we were kidding (Respondent 19).

The process of rendering the physical and emotional violence invisible to others was facilitated by the privacy inherent in most husband/wife interactions. For the most part, the violent events reported in the interviews occurred in the couples' homes, in culturally respected, traditionally private worlds. When the violence or its consequences became public, it challenged the women's public presentations of self and identity:

... [W]e both grew up in town and it's a small place, everybody knows each other, I knew the people who lived two doors away from us. My best friend now, lives across the street, but I knew her as a little girl, her family knew my parents and stuff, and there was all kinds of people on this block that I knew, and I was just-it was mortifying for me...and then one time he did, he hit me in the mouth and stuff, and I was all black and blue and my lip was bleeding, and then I wouldn't want to go outside, you know... (Respondent 19).

The abused women in this study reported actively employing face-saving strategies to keep the violence invisible, even from strangers. Strangers are representative of Mead's (1934) "generalized other" and, as such, were assumed to hold generally conventional views about women who lived in abusive relationships characterizing them as victims, masochists, dependent personalities, and so on-identities that the women were unwilling to assume. In this context, face-saving strategies became very important to presentations of self.

The extremes of face-saving strategies are illustrated in the narrative of one respondent who, grieving her father's recent death plus the stress of the repeated violence from her partner, was forced to leave her job and reported that she finally "flipped out." Her doctors prescribed anti-psychotic drugs. She told this story of maintaining face:

They [the drugs] made me so sick I felt like I was coming out of my skin and I couldn't sleep, I couldn't eat. It was hard to do anything, they were literally destroying my brain...they [the doctors] brainwashed my mother into thinking that (pause 4 seconds) I was schizophrenic. That I was exhibiting all the signs of schizophrenia. Hearing voices, seeing things, extremely paranoid, scared out of my mind, terrified and, um, just delusions. But $I$, the psychiatrist in the psych ward-I failed to tell them that I had ever been beaten up, because I was humiliated. 'Cause they were so, they seemed so together, they were in their 40 s and they were really pretty. They were really pretty, and they were really pretty and dressed really nicely, they seemed really intelligent and capable and they were holding down this incredibly stressful job on a psych ward. And I was so humiliated by the whole thing that I never told them (Respondent 22). 
Although notably extreme in its consequences, this woman's reactions were common to the other women (i.e., paranoia, cognitive dissonance, and numbing fear), and may have been logical and purposeful when viewed within the context of repeated violence and terror. Her own reactions apparently became exacerbated by the psychopharmacological treatment. Nonetheless, she chose not to disclose her lived experiences of violence. The picture that she drew of her abused self in contrast to the medical personnel was too damaging to sustain. She preferred to be labelled "schizophrenic." The violence from her partner had so profoundly impacted her sense of self that a deviant, psychiatric label was preferable to a label of victimization. While her story is extreme in its face-saving tenacity, it is not uncommon in its report of the struggles to maintain presentations of self consonant with social ideologies of harmonious marital relationships.

\section{Contradictory Beliefs}

Another aspect of invisibility was the women's belief that the abusers' control was so penetrating that no one would be able to help them except themselves. This led to simultaneously held contradictory beliefs, that is, that they were the "only" ones who could stop the abuse and yet they were powerless in attempts to halt the violence. This respondent's comments reflect this paradox as well as the bewildering feelings of power and impotence in controlling the violence:

I mean, I'm the only one that can stop him from abusing me, no policeman can. No doctor. Nobody can stop him but me, you know. That's the way I think. I, I, I, I wanted to be with him. I don't want him to be in jail. I wanted to be with him myself. It's fucked up, but (pause) it's the truth... (Respondent 15)

The relationships came to be viewed as all inclusive and determined in their forms. The women's lives were so dominated by the pervasive effects of the violence and by the men's definitional hegemony that they were, for a time, unable to act in their own interests:

...[N]othing's familiar any more, I get-(crying) it gets to where I can't think, I can't make a decision, I'm all mixed up. I start thinking and I feel sick (Respondent 31).

\section{Interactive Processes}

Invisibility remained, however, an interactive process. As reported by the women, their partners also used various strategies to minimize the possible de-privatization of the violence. The men's strategies, as described by the respondents, were very different in nature from the women's. Where 
women focused on their own active, public constructions of their families as happy, the men's strategies focused on maintaining control of the women and of the information that the women expressed publically. By controlling the women, the men apparently were attempting to control any potential disclosures of the violence. They appeared to consider their own violence otherwise invisible.

Various manifestations of men's strategies for maintaining invisibility were reported by their female partners (see Table I). In asserting privilege, for example, this man highlighted his sense of ownership, or his property rights, in regard to his partner:

And as the conversation went on, he said, he said, uh, You're my wife and I can do anything I want to you. (Respondent 4)

Another frequently mentioned strategy to achieve invisibility was controlled assaults. Men located their physical attacks in areas of women's bodies that would not be publically visible:

[B] [Bt after that [assault requiring medical attention] he got wise and he always
hit me in the back of the head, he'd just pound me and pound me and I'd fall
down on the ground and everything. (Respondent 19)

Abusive men were concerned with controlling more than the physical areas of display. They also attempted to control the women's access to other social interactions. They used various interpersonal techniques to accomplish this isolation:

I'm the world's most gregarious person...I never really put two and two together that any time I wanted to do something was such a major inconvenience because he'd harass me. It wasn't until right before I decided to leave that I was watching what he was doing to me and my friends, to make sure I didn't have any. (Respondent 26)

Well, I knew, in all the fights we ever had, he always took away my mobilization, you know. 'You can't drive, you can't do this.' So I was never able to leave. I mean, my solitude in the trailer court was-because it was such a small area-that was my only space that I had [a bathroom tub area]. (Respondent 11)

When social isolation could not be effectively imposed, abusive men attempted to set the parameters for their partners conversational topics.

Table I. Invisibility Strategies Reportedly Utilized by Abusive Males

Assertions of privilege

Controlled Assaults

Social Isolation of Female Partners

Restricting Parner's Communications

Blaming the Victim

Denials of Responsibility

Reconstruction of Abusive Actions 
Their dominance was often so pervasive that even in private conversations the women restricted communication, as these illustrations make clear:

He accused me of mentioning somethin' to her [neighbor] and I told him, I said what goes on between me and you is only between me and you only. I don't go blabbin around. (Respondent 7)

I: And he's saying go see a psychiatrist?

R: Yeah, but um, you know, I-I, he wouldn't ever want me to talk about the relationship, 'cause I'm not ever supposed to talk about that. (Respondent 10)

Blaming the victim and denying personal responsibility were additional strategies reportedly used to privatize the violence. By providing motives for the violence, the men were often able to legitimate their violent actions to their partners. The two would then negotiate the severity, rather than the legitimacy, of the assaults. The following motives were common:

Or he'd say, Well, you know, if you'd do it right, I wouldn't have to do this to you. (Respondent 11)

He was like You don't help me. You don't help me with anything. You don't help me financially. All you do is just lay around on your butt. (Respondent 20)

Sounded like what he was saying to me it's your problem and so I'm going to find someone else and I won't be like that with anybody else. I'm just like that with you because it's your problem. (Respondent 23)

Physically violent events beg interpretation. The explanations that the men reportedly provided were reconstructions of their actions that further resulted in blaming the victim and denying responsibility.

...[A]ny time I did try [expressing feelings] I felt like he was, he would try to make me see how his way was the right way and that it wasn't $O K$ for me to feel the way I felt. He wouldn't just allow me. It wasn't OK for me... (Respondent 1)

And it was like he suddenly turned this whole thing around. And he was making things up, I mean at this point....it was like he wasn't talking about me he was talking about someone else. (Respondent 21)

The men's strategies worked for awhile. When the abusers were successful in making the women complicit in concealing the abuse, the violence remained invisible to others. Ironically, when the women began "telling" others, they often found themselves trapped by the complicity of their own previous presentations of self and situations. When they attempted to make their private experiences of violence public, their reports were often challenged or denied. They had rendered the violence invisible.

Although escalating in degree, the violent relationships were not changing in form. The women were changing within them, although as yet 
unsuccessful either in changing the relationships or countering other people's discounting of their stories.

\title{
STRATEGIES TO CONTAIN THE VIOLENCE
}

Denzin (1984, p. 507) argued that the women in abusive relationships

\begin{abstract}
...deceive themselves into believing that the violence is not real, or does not exist, or will not occur again. By acting as if they accept what they do not believe, they disarm in advance all arguments that might reveal to them that they are deeply embedded in a violent situation that requires some kind of action on somebody's part.
\end{abstract}

The data in this study affirmed that this is particularly true during the "invisibility phase" of the continuing process of strategy development. However, as the abused women's expectations of loving relationships were destroyed, and as the relationships became increasingly unpredictable and abusive, invisibility was no longer a viable option. The women then employed other strategies. They initially attempted to preserve the marital relationship, to figure out the reasons for and the effects of the violence, and to keep it from occurring again.

\section{Problem Solving Strategies}

"The meanings the woman attaches to the violence and the resources she believes she has shape strategies for living with, or ending, the violence" (Mills, 1985, p. 107). The women's strategies were aimed at controlling the risks of violence, that is, the potential for physical, psychological, and emotional damage. They employed what Chang (1989) has identified as problem solving and coping strategies, that is, strategies to control the violence and strategies to keep the sense of self intact. The distinctions between problem solving and coping, or self-preservation, became blurred as the abuse became frequent, public, and more violent.

Analytically problem solving strategies focussed primarily on managing the violence. Strategies included rationalization, minimizing the significance of the violence to self and/or others, and self-blame. While analytically discrete, the use of these agentic processes was often simultaneous, overlapping, and circular. A woman might use all or one, separately or in combination, but all of the women reported utilizing some of the strategies to manage the violence and its effects. The following retrospective recountings illustrate these processes: 
Rationalizing: ...[E]ven if it's bad, it's what you get used to and what you think...pretty soon you don't know the difference... (Respondent 31).

Minimizing the significance of the violence: When I was seeing somebody else, he'd go and threaten them, or smash his windows in his car, or something...and he persisted, more and more, which I didn't realize was violence. I really thought it was just flattery, I guess (Respondent 4).

Self Blame: "Um, sometimes I think, sometimes I think it's my fault because (pause 4 seconds) um, I would make something big, you know like, something little, I would really make it big, and then he would respond and hit me. (Respondent 14)

Despite active attempts at management, the violence usually continued unabated. While the strategies did not significantly change the violence, they profoundly altered the ways that the women experienced themselves. Mills (1985) has maintained that the abused woman loses her "observing self" (i.e., becomes excessively passive and barely reacts to her social environment). Rather than a loss of self, this study found that passivity is an active strategy of survival. It is not, as Walker (1979) contended, an identity. Passivity labeled as an identity is a view from the outside. From the viewpoint of the actor, passive resistance was a strategic mode of action undertaken in preservation of self. At times, survival was contingent on restraining any overt expression of self definition. Each woman who reported this strategy described becoming an invisible presence:

I-I just, I, you know, I just did all the shit I do. I just go limp. I just act however he wants me to act. I just go limp...I just shut up. He was, I just shut up. I quit talking. And I quit, I just leave. I just watched TV. Eat...Just entertain. Just watch TV. Don't say nothin'. Don't ask for anything, you know, just try to keep quiet. (Respondent 15)

Respondents made strategic decisions. Although they appeared to acquiesce to the abusers' controls and definitions, the women continued to harbor alternative interpretations. They survived life-threatening experiences by developing adaptive strategies of resistance and strength. Choosing passivity was one such strategy.

\section{Self-Preservation Strategies}

Self-preservation strategies included practices such as fantasies of murder. Many respondents reported fantasies and fictionalized plans to initiate their partners' demise. One respondent actually told her husband, a foreign national, that if the violence didn't stop, one weekend when they were in Tijuana, she would kill him, cross the border into the U.S. and return alone. "No one will care. Another Mexican down." She was able to empower herself with a fantasy that employed her own direct action, the expectations 
of institutional classism and racism that would support the credibility of her fantasy, and the effect of the psychological threat of uncertainty on her partner. It was for her a sustaining fantasy.

Some respondents rejected contemplations of homicide because of the meaning such an act would have for their own identities-they would have become as violent as their partners:

I don't like to think about murder, because then I've become as violent as he has and that's something I don't like. When I yell back or become violent, then I've become as violent as he has, and that's kind of the lowest of the low. (Respondent 31)

Other respondents turned to fantasies of suicide:

At one point, I thought the only thing was killing me and my kids so that he couldn't get to us. And that didn't seem like a real good alternative, but I did consider that (pause) on more than one occasion. (Respondent 2)

Notions of murder and suicide were seductively powerful because they imbued the women with senses of their own autonomy in devising a vision, or hope, of a way out. They were acts that offered instant relief and resolutions of ambiguity. The women could make decisions and take actions that would prevent the abusers from causing any further damage to, or destruction of, those aspects of self which gave meaning and value to life. While often actively contemplating murder and/or suicide, they chose to rely on other strategies.

Outcomes of problem solving and self-preservation strategies varied. If the women could meet all the abusers' demands all of the time, then the violence could potentially be contained. But the men could destabilize at any time. All of the women believed they had tried "everything" that they could think of to make the relationships "work," that is, be nonviolent. They exhausted their individual resources believing that they could succeed in changing the relationships and ending the violence. They remained hopeful of successful outcomes as long as they had new strategies, new plans, something new to try to resolve the relational problems, and they were very resourceful in developing fresh strategies.

\section{Individual Solutions}

When the women's repertory for managing the violence and preserving agency were not successful, their senses of self were undermined. Most looked to personal solutions to resolve what is, essentially, a social problem. What they did not do was examine the cultural expectations of the conventions of the relationship: 
So I really tried. I thought, well, it's me. I'm not pleasing him. So I tried to really be a good wife. I won't take as many classes. I'll really concentrate on making the marriage work. I'll keep the house really clean and I'll do his laundry and I'll cook him his meals and I'll do everything to make him happy so that he won't be unhappy anymore...And ha, ha, you know, I mean it doesn't matter what you've done. They're still going to find something to explode about. (Respondent 23)

The problem was most often identified as an individual error of choice (i.e., choosing the wrong partner), not as a problem of institutionalized ideology. Only one respondent recognized the social implications of her individual experience:

\begin{abstract}
...[L]ook we live in a sexist society and this is, you're a victim of sexism, and this is, this is how sexism, cause it's empowering to name the fucking thing, you know, it's like otherwise we just go, you know, "I'm sort of an emotional wreck and I just sort of drew this down upon my head and I'm so unlucky and I'm kind of a weirdo type that attracts these creeps, and, yeah, you know, you get all these different, you know, I'm useless or I'm this," or I think it's really empowering to say, Look sister, sisters, you know it's like, politics helps me because polities is about power and it also gets you out of misery and into anger, into a fight back. (Respondent 15)
\end{abstract}

For most of the women in the study, however, their violent experiences were interpreted solely as personal and idiosyncratic, and largely as consequential of their own shortcomings and failures. Isolation in the definitional dialogues made it difficult for the women to access other perspectives on the violence. This definitional isolation made outside input more important as it was eventually perceived as "objective" information. Some abused women who have not come to public awareness, have probably settled for whatever relief their own strategies and actions could bring. Recurrence of the violence, however, led most of these respondents to redefine the abuse into a problem to be managed. They reported the need to try something new that might provide them not only with the means of abating or stopping the violence but also with explanations for it. They began to supplement their individual strategies and to request outside help in order to turn the dialogue into a multilog. They reached out for other perspectives on their situations and they began to tell outsiders about their experiences. Most respondents stated clearly that initially they were not trying to leave their relationships. Within the contradictions of the violence, they loved their partners and believed that their partners loved them:

...he was, like, my best friend, you know-it's kind of like, beat the dog, and then pat it, you know-I don't know how to explain it, you know, it's like, he is your best friend, the person that you rely on for all the affection that you're gonna get... (Respondent 11)

Committed to the success of the relationships, they were trying to develop definitions consonant with their experiences and with their partners' 
explanations. Telling others was another strategy for change. Because violence is only one aspect of an abusive relationship, women strategized to eliminate the violence and to maintain the affectionate qualities in the relationships. Initially, assistance was sought to bolster the relationships. This respondent articulates her frustration with other-defined, albeit well-intentioned, offers of assistance:

\begin{abstract}
Well, it depends on what kind of help, these people think that if I call them, they'll come and get me and I'll stay with them, but that's not the help, that's what I felt like in the meetings I come to, everyone says, the guy's a jerk and you're all right, don't let him make you think it's you and they give you all these ways of getting a place to stay or food to eat, but they don't tell you how to go back and deal with the person and I bet you nine out of ten of them go back, end up seeing the person again because you're not learning how to deal with it at the time, you're learning how to run away, you know what I mean? (Respondent 31)
\end{abstract}

\title{
MAKING THE INVISIBLE VISIBLE
}

In examining violent relationships, it is important also to explore some generally accepted social definitions of abuse because these definitions come to be experienced as "objective reality" in one form or another (Estes, 1981). Abused women tell others about their private experiences within a social context that is framed by these public definitions. Hegemonic, socially structured definitions delineate the power of individuals and groups, as well as the available opportunities. Opportunities include access to alternative definitions of reality and the imposition of limits on possibilities. Alternatives are not possible if they are not conceivable, as noted by Alford (1976, p. 7) "[people] come to accept as inevitable that which exists and even believe that it is right."

When these women began telling others about the violence in their lives, they did so within the context of social definitions about wife abuse. While the label itself identifies the type of actors, "wife" and implicitly "husband," and the type of problem, "abuse," it has also come to imply an assignment of responsibility for the problem: that is, husbands produce wives as victims (Loseke, 1987). Such reductionism obscures the reciprocal processes of influence in abusive relationships. Both parties make contributions, positive and negative, to the on-going interactions. Actions taken by both parties contribute to the violent events. It disempowers abused women to continuously cast them as powerless, passive victims of violence. The men are not always totally responsible and the women are not always totally innocent. Yet it is also problematic to assign equal blame. Most intimate heterosexual relationships do not involve a reciprocity of equals. So- 
cially and culturally, women as a group command fewer resources of all types than men resulting in an inherent imbalance of power. The cumulative effects of abuse further diminish women's already limited social power. The two interactants are coacting, but they are not equals.

Additionally, the social definitions of abuse focus primarily on physical assaults. Emotional pain is not readily observable, therefore, it is difficult to establish causal relationships between men's emotionally abusive actions and women's pain. Emotional battering is related to internal states. Consequently, its invisibility makes it easier to blame the women for being "masochistic," "dependent," and "insecure" (Ferraro, 1979). Yet, when women in this study talked about physical assaults, they also talked about the emotional abuse that went with them, as in this typical recounting:

R:The physical attack didn't bother me amazingly enough as much as the verbal attack. The verbal attack was much more abusive, I thought, much more, much more devastating.

I: Why?

R: Well, because a physical attack is just physical. It's your body. Whereas a verbal attack, you know, they get into you, the person, and, um, it's more emotional and psychological. I mean my face healed. But the stuff he did to my mind, it hasn't even healed to this day and it's been, you know, l've been separated from him for over a year now. (Respondent 21)

Valentine (1990) has argued that body is fused with a sense of self and that women's bodies are vehicles of self through which men try to exercise control of women's identities. In the abusive situations described by these respondents, men's control was enacted on body surfaces through physical assaults and on interiors through emotional abuse. Women's bodies became the arenas where men located their control. If as Valentine $(1990$, p. 4) asserted "In women's experience the socially controlled, socially interpreted outer body's surfaces are a source of statements about our value, a locus of definitions of women's moral worth," then abusive assaults can be construed as assaults on women's self-worth and self-value, not just as physical chastisement.

Emotional abuse attacks the sense of self. Many women eat, sleep, play, and work within the closed system of the family. Most daily interaction occurs with an audience of men and children. Even if women are employed outside the home, the potential for perspectives to counter those put forth by the abusers is limited if women's significant identities remain deeply embedded in their relationships.

Husband and wife interactions, unlike most social roles with limited activity, cover a wider variety of continuous contact. Eating, sleeping, playing, and sexual activity are filled with unremitting intimacy. Intimate relationships are not formally structured, like work or organizational activities, so rules and definitions are not as clearly delineated (Gross, 1987). Addi- 
tionally, families are private affairs. The impacts, then, of men's definitional hegemony within the social context of family can be pervasive.

Nonetheless, these respondents continued to maintain some distinctive internal definitions of self and situation and to develop problem solving and coping strategies to resolve the conflicts and to end the violence. Over time, they began to feel that their efforts to eliminate the violence were unavailing. Their definitions of the situations (i.e., that they could stop the violence by altering their actions), and their senses of competence were being undermined by the continuing abuse. Nonetheless, they continued to seek and to create new strategies and in the process they strengthened their own agency.

\section{CONCLUSION}

Placing women and their experiences at the center of this analysis illuminates the simultaneity of love and violence that forms the contextual frame within which abused women develop agency. Previous substantive research and theoretical constructs related to issues of wife abuse and/or domestic violence, while commenting upon the existence of this phenomenon, have neglected the analytical importance of these contradictions as women construct meaning and devise strategies to survive, as this respondent related:

1 don't know how to get out of this relationship and just cut it off because I have some love-I love him and it's not good for me, it's not healthy. (Respondent 25)

While the violence was experienced by the women as individual and idiosyncratic, intimate, interpersonal abuse simultaneously incorporates, mirrors, and re-interprets broader patterns of social, political, economic, and ideological relations between men and women. Social power inequities manifest in intimate violence at the interactional level. Emotional and psychological violence began in the definitional dialogues between these partners, initiated before any physical violence occurred and continued throughout the courses of the relationships. The micro level dialogues reflect in a conspicuous manner the routine establishment and maintenance of hierarchical arrangements in macro level male/female relations. They are the outcomes of the social organization of domestic arrangements in the homes of abused women and in the more public arenas of contemporary life.

Within contradictory interactional contexts, these abused women developed strategies intended to halt, change, or cope with their partners' violence. They supported the public authenticity of the men's definitions and, in so doing, they rendered the violent acts invisible to others and further minimized these actions to themselves. 
The interactive nature of these relationships was further constructed and defined by the women experiencing the violence through the meanings they ascribed and the strategies they developed to manage the violent episodes, publically and privately. As the women struggled to develop agency, processes emerged that highlighted the ways that the women interpreted the violence and its inherent contradictions. These interpretations and the women's subsequent actions were predicated on social definitions of women, wives, families and abuse.

Within the domain of male/female interactions, structural conditions-historical, political, economic, social and cultural constraints-have patterned stratification systems of gender inequality. While social institutions have promoted "traditional" values of gender hierarchy, other feminist and humanist models have developed to challenge these constructions. Sociologically, there is a need to examine more fully how concepts of family, intimacy, home, marriage, and power contribute to violence against women in intimate environments. This paper was a contribution to the expansion of that discourse. Perhaps from these new perspectives, broader social strategies for preventive and ameliorative actions regarding violence against women will be developed.

\section{ACKNOWLEDGMENTS}

I am grateful to Beth Hess, Adele Clarke, Eileen Moran, and Anselm Strauss for many helpful insights and suggestions. Further, I wish to acknowledge my California writers' group colleagues Theresa Montini, Petra Liljestrand, and Patricia Flynn for comments and criticisms on earlier drafts.

\section{REFERENCES}

Allen, C. M., and Straus, M. A. (1980). Resources, power and husband-wife violence. In Hotaling, M. A., and G. T. (eds.), The Social Cases of Husband-Wife Violence, University of Minnesota Press, Minneapolis, pp. 68-81.

Alford, R. (1976). Health Care Politics, University of Chicago Press, Chicago.

Bernard, J. (1975). Women, Wives, Mothers: Values and Options, Aildine Publishing Co., Chicago.

Chang, D. B. K. (1989). An abused spouse's self-saving process: A theory of identity transformation. Sociological Perspect. 32: 535-550.

Charmaz, K. (1983). The grounded theory method: An explication and interpretation. In Emerson, R. M. (ed.), Contemporary Field Research, Little, Brown and Company, Boston, pp. 109-126.

Cho, J. (1991). Ressentiment of the battered wives: The case of Korea. Studies in Symbol. Interact. 12: 149-181.

Denzin, N. K. (1989). Interpretive Interactionism, Sage, Newbury Park. 
Denzin, N. K. (1984). Toward a phenomenology of domestic, family violence. Am. J. Sociol. 90: 483-513.

Dobash, R. E., and Dobash, R. P. (1979). Violence Against Wives, Free Press, New York.

Dobash, R. E., and Dobash, R. P. (1981). Community response to violence against wives: Charivari, abstract justice and patriarchy. Social Probl. 28: 563-581.

Dobash, R. E., and Dobash, R. P. (1992). Women, Violence and Social Change, Routledge, London.

Dobash, R. E., Dobash, R. P., Cavanagh, C, and Wilson, M. (1978). Wife beating: The victims speak. Victimology, 2: 608-622.

DuBois, B. (1983). Passionate scholarship: Notes on values, knowing, and method in feminist social science. In Bowles, B., and Klein, R. D. (eds.), Theories of women's studies, Routledge \& Kegan Paul, London and New York, pp. 105-116.

Estes, C. (1981). The social construction of reality:A framework for inquiry. The Aging Enterprise, Jossey-Bass Publishers, San Francisco.

Ferraro, K. J. (1979). Physical and emotional battering: Aspects of managing hurt. Calif. Sociologist, 2: 134-149.

Ferraro, K. J. (1987). Negotiating trouble in a battered women's shelter. In Deegan, M. J., and Hill, M. R. (eds.). Women and symbolic interaction, Allen \& Unwin, Boston, pp. 379-394.

Ferraro, K. J., and Johnson, J. M. (1983). How women experience battering: The process of victimization. Social Probl. 30: 325-339.

Gelles, R. J., and Straus, M. A. (1979). Violence in the American family. J. Social Issues 35: 15-39.

Giles-Sims, J. (1983). Wife Battering: A Systems Theory Approach. The Guilford Press, New York.

Glaser, B. G. (1978). Theoretical Sensitivity, The Sociology Press, Mill Valley, CA.

Glaser, B. G., and Strauss, A. L. (1967). The Discovery of Grounded Theory, Aldine de Gruyter, New York.

Goffman, E. (1971). Relations in Public, Harper \& Row, Publishers, New York.

Gross, H. E. (1987). Couples who live apart: Time/Place disjunctions and their consequences. In Deegan, M. J., and Hill, M. (eds). Women and Symbolic Interaction, Allen \& Unwin, Inc., Boston, pp. 211-228.

Hanmer, J., and Maynard, M. (1987). Women, Violence and Social Control, Humanities Press International, Atlantic Highlands.

Hickey, M. C. (1990). The double life of the battered wife. Working Mother 13: 38-44.

Keller, E. F. (1985). Reflections on Gender and Science, Yale University Press, New Haven.

Kelly, L. (1988). How women define their experiences of violence. In Yllo, K, and Bograd, M. (eds.). Feminist Perspectives on Wife Abuse, Sage Publications, Newbury Park, pp. 114-132.

Kurz, D. (1989). Social science perspectives on wife abuse: Current debates and future directions. Gender Soc. 3: 489-505.

Lasch, C. (1978). Haven in a Heartless World, Basic Books, New York

Lempert, L. B. (1992). The crucible: violence, help-seeking, and abused women's transformations of self, Unpublished doctoral dissertation, The University of California, San Francisco.

Lempert, L. B. (1995). The line in the sand: Definitional dialogues in abusive relationships. Studies Symbol. Interact. 18.

Loseke, D. R. (1987). Lived realities and the construction of social problems: The case of wife abuse. Symbol. Interact. 10: 229-243.

Martin, D. (1976). Battered Wives, Pocket Books, New York.

Mead, G. H. (1934). Mind, Self, and Society, University of Chicago Press, Chicago.

Mills, T. (1985). The assault on the self: Stages in coping with battering husbands. Qualitative Sociology 8: 103-123.

Mintz, S., and Kellogg, S. (1988). Domestic Revolutions: A Social History of American Family Life, The Free Press, New York.

Pagelow, M. D. (1981). Woman-Battering: Victims and Their Experiences, Sage Publications, Beverly Hills. 
Pagelow, M. D. (1984). Family Violence, Praeger, New York.

Radford, J. (1987). Legalising woman abuse. In Hanmer, J., and Maynard, M. (eds). Women, Violence and Social Control, Humanities Press International, Atlantic Highlands, pp. 135-151.

Rubin, L. (1983). Intimate Strangers, Harper \& Row, Publishers, New York.

Sheffield, C. J. (1989). The invisible intruder: women's experiences of obscene phone calls. Gender Society, 3: $483-488$.

Skolnick, A. S., and Skolnick, J. H. (1992). Family in Transition (7th edition), Harper Collins Publishers, New York, pp. 1-17.

Straus, M. A. (1987). A sociological perspective on the prevention and treatment of wife beating. In Roy, M. (ed.), Battered Women, Van Nostrand Reinhold, New York.

Straus, M. A., Gelles, R. J., and Steinmetz, S. (1980). Behind Closed Door, Doubleday, Garden City, NY.

Straus, M. A., and Gelles, R. J. (1986). Societal change and change in family violence from 1975 to 1985 as revealed by two national surveys. J. Marr. Fam. 48: 465-479.

Strauss, A., \& Corbin, J. (1990). Basics of Qualitative Research, Sage, Newbury Park.

Strauss, A. L. (1987). Qualitative Analysis for Social Scientists, Cambridge University Press, Cambridge.

Valentine, C. G. (1990). Appearance, norms, gender's body and the social control of women. Paper presented at the Annual Meeting of the American Sociological Association, Washington, D.C., August 1990.

Walker, L. E. (1979). The Battered Woman, Harper \& Row, Publishers, New York.

Walker, L. E. (1989). Terrifying Love, Harper \& Row, Publishers, New York. 